\title{
Postępowanie u pacjentki z bólem neuropatycznym po ekstrakcji trzeciego zęba trzonowego żuchwy. Opis przypadku
}

\author{
Neuropathic pain after a third molar extraction. A case report
}

\author{
Bartosz Dalewski ${ }^{\circledR}$, Agata Kamińska², Grzegorz Trybek³, Bogumiła Frączak \\ ${ }^{1}$ Pomorski Uniwersytet Medyczny w Szczecinie, Katedra i Zakład Protetyki Stomatologicznej, al. Powstańców Wlkp. 72, 70-111 Szczecin \\ Pomeranian Medical University in Szczecin, Chair and Department of Prosthodontics \\ ${ }^{2}$ Uniwersytecka Klinika Stomatologiczna Pomorskiego Uniwersytetu Medycznego w Szczecinie, Poradnia Protetyki Stomatologicznej, \\ al. Powstańców Wlkp. 72, 70-111 Szczecin \\ University Dental Clinic of the Pomeranian Medical University in Szczecin, Clinic of Prosthodontics \\ ${ }^{3}$ Pomorski Uniwersytet Medyczny w Szczecinie, Zakład Chirurgii Stomatologicznej, al. Powstańców Wlkp. 72, 70-111 Szczecin \\ Pomeranian Medical University in Szczecin, Department of Dental Surgery \\ $\triangle$ bartosz.dalewski@pum.edu.pl
}

\begin{abstract}
Introduction: Among adult patients attending a general practitioner, up to $20 \%$ suffer from chronic pain. In this group there are patients with symptoms of neuropathic pain. It is caused by damage to the sensory components of the nervous system. Case report: This is the case of a 23-year-old female patient who was referred to the Clinic of Prosthodontics at the University Dental Clinic of the Pomeranian Medical University in Szczecin (Poland) for the treatment of neuropathic pain triggered by an incorrect surgical procedure during the extraction of tooth 48 .
\end{abstract}

Pharmacological treatment was implemented using drugs from the group of analgesics, antidepressants and antiepileptics, as well as several courses of dry needling and behavioural therapy. In addition, the patient uses a stabilization appliance due to secondary bruxism, which probably occurred throughout the entire pain management. Pain in the Visual Analogue Scale (VAS) plunged during therapy from VAS $=7$ to VAS $=0$. The patient attends regular control appointments.

Keywords: chronic pain; neuropathic pain; occlusal appliance; extraction; dry needling.

\begin{abstract}
ABSTRAKT
Wstęp: Spośród pacjentów dorosłych zgłaszających się do lekarza podstawowej opieki zdrowotnej do $20 \%$ cierpi z powodu bólu przewlekłego. W grupie tej znajdują się pacjenci zgłaszający dolegliwości o charakterze bólu neuropatycznego. Ból neuropatyczny jest spowodowany uszkodzeniem czuciowych składowych układu nerwowego.

Opis przypadku: W pracy przedstawiono przypadek 23-letniej pacjentki, która zgłosiła się do Poradni Protetyki Stomatologicznej Uniwersyteckiej Kliniki Stomatologicznej Pomorskiego Uniwersytetu Medycznego w Szczecinie w celu leczenia bólu neuropatycznego zainicjowanego poprzez nieprawidłowe
\end{abstract}

postępowanie chirurgiczne podczas ekstrakcji zęba 48 . U pacjentki przeprowadzone zostało postępowanie farmakologiczne z użyciem leków z grupy przeciwbólowych, przeciwdepresyjnych oraz przeciwpadaczkowych wg schematów właściwych dla leczenia bólu neuropatycznego. Dodatkowo wykonanych zostało kilka zabiegów igłowania suchego. Ponadto pacjentka użytkuje szynę stabilizacyjną ze względu na zdiagnozowany w czasie leczenia bruksizm typu wtórnego. Pacjentka uczęszcza na regularne wizyty kontrolne. Dolegliwości bólowe w skali VAS zmieniły się $\mathrm{w}$ trakcie terapii $\mathrm{z}$ VAS $=7$ do VAS $=0$.

Słowa kluczowe: ból przewlekły; ból neuropatyczny; szyna okluzyjna; ekstrakcja; igłowanie suche.

\section{WSTĘP}

Ból przewlekły to z definicji ból utrzymujący się dłużej niż wynosi okres prawidłowego gojenia się uszkodzenia lub ból utrzymujący się dłużej niż 3 miesiące. Typem bólu przewlekłego jest ból neuropatyczny, który spowodowany jest uszkodzeniem czuciowych składowych układu nerwowego $[1,2]$.

W wywiadzie pacjenci opisują ból jako przeszywający, palący, w obszarze mrowienia/drętwienia, o charakterze ciągłym lub z okresami remisji [3]. Ból taki może być zlokalizowany, promieniować lub być rzutowany. Ponadto mogą występować czynniki modulujące jego odczuwanie lub autonomiczne objawy towarzyszące [4, 5]. Model biopsychospołeczny pacjentów cierpiących z powodu bólu przewlekłego wymaga od lekarza uwzględnienia wielowymiarowego, subiektywnego charakteru doświadczania bólu oraz dobrania odpowiedniego dla danego przypadku leczenia [6, 7].

W przypadku występowania dolegliwości bólowych, mimo braku postawienia adekwatnego rozpoznania, należy wziąć pod uwagę następujące przyczyny:

- niekontrolowaną cukrzycę,

- niedobory witamin,

- ekspozycję na toksyny bądź leki,

- zakażenie HIV, 
- zespoły paranowotworowe,

- neuropatie dziedziczne (erytromelalgia, amyloidoza),

- neuropatie nabyte (cukrzycowa, popółpaścowa) [8, 9, 10].

Dotychczasowe metody leczenia bólu przewlekłego opierają się na połączonych:

- leczeniu farmakologicznym,

- terapii poznawczo-behawioralnej,

- ćwiczeniach fizycznych,

- akupunkturze/igłowaniu suchym wraz z innymi zabiegami z zakresu medycyny alternatywnej i komplementarnej,

- celowanej fizjo- i fizykoterapii $[2,4,11,12]$.

\section{OPIS PRZYPADKU}

Do Poradni Protetyki Stomatologicznej (PPS) Uniwersyteckiej Kliniki Stomatologicznej (UKS) Pomorskiego Uniwersytetu Medycznego w Szczecinie (PUM) zgłosiła się pacjentka K.A. w wieku 23 lat z powodu bólu przewlekłego trwającego od 10 miesięcy, który pojawił się po operacyjnym usunięciu zęba 48.

W wywiadzie kobieta podała, iż od początku wystąpienia dolegliwości kilkakrotnie była już w gabinecie, w którym był wykonywany zabieg, gdzie zgłaszała ból w miejscu ekstrakcji oraz nieprawidłowe gojenie. Lekarz, który wykonywał ekstrakcję, po zbadaniu pacjentki uznał stan miejscowy za prawidłowy, a zgłaszane dolegliwości zostały przez niego zbagatelizowane. Pacjentka zrezygnowała z usług gabinetu i zgłosiła się do innego lekarza. Dopiero wtedy, po ok. 30 dniach od pierwszego zabiegu, zostało wykonane zdjęcie pantomograficzne, które wykazało pozostawienie dwóch korzeni zęba 48 (ryc. 1). Wykonany został kolejny zabieg, podczas którego pozostawione poprzednio 2 korzenie zęba 48 zostały usunięte operacyjnie, a ranę zaopatrzono w sposób chirurgiczny. Pomimo tego działania nadal utrzymywały się dolegliwości bólowe. Po drugim zabiegu pacjentka odwiedziła kilka prywatnych gabinetów, w których nie uzyskała pomocy w kwestii leczenia występujących u niej dolegliwości bólowych (ryc. 2 i 3).

Na pierwszej wizycie w PPS UKS PUM pacjentka opisała swoje dolegliwości bólowe jako ból ciągły w miejscu po ekstrakcji, w skali VAS = 6-7. W badaniu nie stwierdzono objawów kompresji lub urazu nerwu zębodołowego dolnego.

Z chorób towarzyszących pacjentka podała GERD oraz przepuklinę rozworu przełykowego. Ponadto na podstawie badania oraz wywiadu stwierdzony został bruksizm. W pierwszym schemacie leczenia kobieta otrzymała następujące leki:

- Gabapentin - 2×100 mg/dobę, po 3 dniach $2 \times 200 \mathrm{mg} /$ dobę, po kolejnych 3 dniach $2 \times 300 \mathrm{mg} /$ dobę,

- Nimesulide $-2 \times 100 \mathrm{mg} /$ dobę,

- Pantoprazole $20-2 \times 20 \mathrm{mg} /$ dobę.

Pobrano wyciski do szyny stabilizacyjnej wg Okesona [4].

\section{Wizyta 2.}

Na pierwszej wizycie kontrolnej, która miała miejsce po 7 dniach, pacjentka określiła dolegliwości bólowe w skali VAS na 4-6 oraz wystąpienie objawów niepożądanych w postaci:

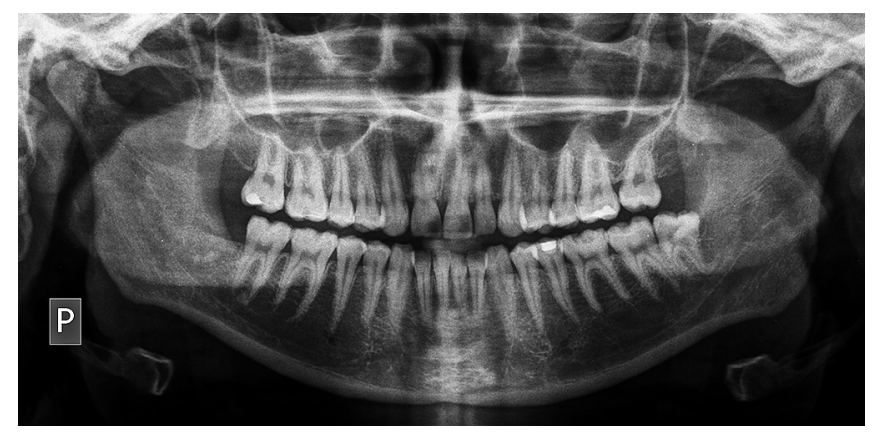

RYCINA 1. Rzut operowanego miejsca na zdjęciu pantomograficznym z widocznymi pozostałościami korzeni zęba 48

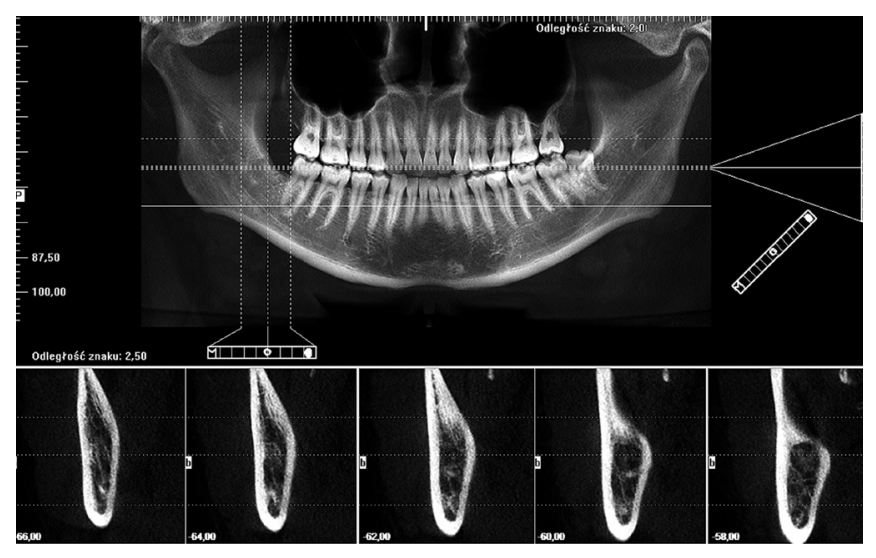

RYCINA 2. Stan po rewizji zębodołu z widocznym w CBCT nieznacznym zagęszczeniem tkanki kostnej i ozębnej w okolicy kanału nerwu zębodołowego dolnego

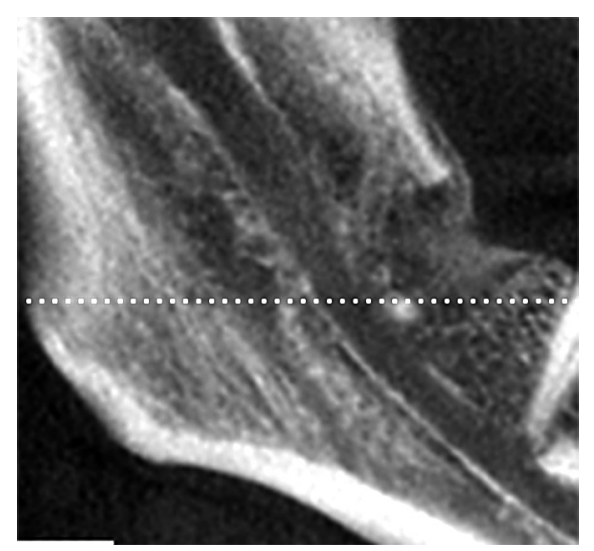

RYCINA 3. Widoczne bezpośrednie sąsiedztwo nerwu zębodołowego dolnego, okolicy w fazie gojenia. Ze względu na lokalizację potencjalne ryzyko związane z kolejnym zabiegiem operacyjnym przewyższa możliwe korzyści

dysfagii, ostrego bólu głowy, zaburzeń widzenia nasilających się wraz ze zwiększaną dawką gabapentyny. Zalecono odstawienie gabapentyny oraz nimesulidu. Zmieniono schemat dawkowania:

- Tramadol hydrochloride + Paracetamol $375 \mathrm{mg}+325 \mathrm{mg}-$ $2 \times 1$ tabletka/dobę,

- Axolan - $2 \times 1$ tabletka/dobę,

- Pantoprazole 20 - 2× $20 \mathrm{mg} /$ dobę.

Na tej wizycie została również oddana szyna zwarciowa wraz z zaleceniami odnośnie do jej użytkowania. 


\section{Wizyta 3.}

Wizyta 3. miała miejsce po 7 dniach od 2. wizyty. Pacjentka podawała, iż podjęła próbę stosowania gabapentyny, jednak nadal występowały objawy niepożądane w postaci bólu głowy. Dolegliwości bólowe w miejscu po ekstrakcji określone zostały przez pacjentkę jako 4-5 w skali VAS. Ze względu na występujące objawy niepożądane zalecono odstawienie gabapentyny. Na tej wizycie została również skorygowana szyna zwarciowa. Schemat dawkowania leków został ponownie zmieniony:

- Amitryptyline hydrochloride $10 \mathrm{mg}-1 \times 10 \mathrm{mg} /$ dobę,

- Tramadol hydrochloride + Paracetamol 375 mg + 325 mg $2 \times 1$ tabletka/dobę,

- Tramadoli hydrochloridum 50 mg - w razie bólu,

- Axolan - $2 \times 1$ tabletka/dobę,

- Pantoprazole 20 - 2×20 mg/dobę.

\section{Wizyta 4.}

Wizyta 4. miała miejsce po 4 tygodniach od 3. wizyty. Pacjentka mówiła o znacznej poprawie. Ocena bólu w skali VAS została określona jako 0-1, okresowo wzrastająca do 3-4 po spożyciu błonnika oraz cytrusów. Nie zaobserwowano objawów wzrostu poziomu serotoniny.

Błonnik pokarmowy oraz zawarte w cytrusach pektyny zmniejszają wchłanianie amitryptyliny, wpływając tym samym na obniżenie skuteczności działania leku [13]. Zalecono dietę ograniczającą spożycie błonnika oraz cytrusów. Schemat leczenia pozostawiono bez zmian:

- Amitryptyline hydrochloride $10 \mathrm{mg}-1 \times 10 \mathrm{mg} /$ dobę,

- Tramadol hydrochloride + Paracetamol 375 mg + 325 mg $2 \times 1$ tabletka/dobę,

- Tramadoli hydrochloridum 50 mg - w razie bólu,

- Axolan $-2 \times 1$,

- Pantoprazole $20-2 \times 20 \mathrm{mg} /$ dobę,

- Vit D3 1000 j. - 1× 1 tabletka/dobę.

\section{Wizyta 5.}

Wizyta 5. miała miejsce po 2 tygodniach od 4. wizyty. Pacjentka podała nawrót dolegliwości w skali VAS = 3. Zwiększono dawkę amitryptyliny do $25 \mathrm{mg}$ na dobę, natomiast dawkowanie pozostałych leków pozostało bez zmian.

\section{Wizyta 6.}

Wizyta 6. miała miejsce po 4 tygodniach od 5. wizyty. Pacjentka podała utrzymujące się dolegliwości bólowe na poziomie 3 w skali VAS, zlokalizowane głównie w okolicy po usuniętym zębie 48.

Podjęto decyzję o skierowaniu pacjentki na badanie CBCT szczęki i żuchwy, a następnie na konsultację do Zakładu Chirurgii Stomatologicznej PUM. Schemat dawkowania leków pozostawiono bez zmian.

\section{Wizyta 7.}

Wizyta 7. miała miejsce po 3 tygodniach od 6. wizyty. Dolegliwości w skali VAS utrzymywały się na poziomie 1-2. Do objawów bólowych dołączyły objawy ze strony przewodu pokarmowego związane z GERD. Ustalono schemat dawkowania leków:
- Amitryptyline hydrochloride - $35 \mathrm{mg} /$ dobę,

- Pantoprazole 20 - 2×20 mg/dobę,

- Gastrotuss - $3 \times /$ dobę po $20 \mathrm{~mL}$ po posiłku.

Zalecono odstawienie stosowanych leków niesteroidowych przeciwzapalnych (NLPZ) oraz wizytę u lekarza podstawowej opieki zdrowotnej w związku z objawami nadkwaśności. Ze względu na złożony proces odczuwania bólu przez pacjentów cierpiących z powodu bólu przewlekłego zalecono umiarkowany tlenowy wysiłek fizyczny 2-3 razy w tygodniu.

\section{Wizyta 8.}

Wizyta 8. miała miejsce po 4 tygodniach od 7. wizyty. Pacjentka podawała dolegliwości bólowe na poziomie 0-1 wg VAS. Zalecono Amitryptyline hydrochloride $-35 \mathrm{mg} /$ dobę.

\section{Wizyta 9.}

Wizyta 9. miała miejsce po 7 dniach od 8. wizyty. Po ocenie CBCT w Zakładzie Chirurgii Stomatologicznej PUM stan gojenia tkanek po ekstrakcji uznany został za prawidłowy. Dawkę amitryptyliny zwiększono do $45 \mathrm{mg}$. Ponadto pacjentka zaczęła przyjmować dekslanzoprazol przepisany przez gastroenterologa. Zalecono: Amitryptyline hydrochloride $-45 \mathrm{mg} /$ dobę oraz Dekslanzoprazol - $2 \times 30$ mg/dobę.

\section{Wizyta 10.}

Wizyta 10. miała miejsce po 7 dniach od 9. wizyty. Pacjentka miała dobre samopoczucie i nie zgłaszała dolegliwości bólowych. Dawka dobowa amitryptyliny wynosiła 45 mg. Ból powracał tylko po spożyciu cytrusów i błonnika.

Po wcześniejszych dolegliwościach pozostał jedynie nieznaczny ból mięśniowo-powięziowy po stronie prawej, obecny prawdopodobnie ze względu na wzrost stężenia neuromediatorów spowodowany przez zażywanie przepisanych leków. Wykonano igłowanie suche mające działanie miejscowo uśmierzające ból i rozluźniające mięśnie szkieletowe [14].

\section{Wizyta 11}

Wizyta 11. miała miejsce po 7 dniach od 10. wizyty. Ponownie wykonano igłowanie suche. Pacjentka nie podawała dolegliwości samoistnych ze strony zębodołu 48, jednak powracały one przy próbie zmniejszenia dawki amitryptyliny. Dawkowanie tego leku pozostawiono więc na poziomie $45 \mathrm{mg}$ na dobę.

\section{Wizyta 12.}

Wizyta 12. miała miejsce po 7 dniach od 11. wizyty. Ponownie wykonano igłowanie suche. Po ponad 5 miesiącach od pierwszej wizyty pacjentka podała nawrót dolegliwości bólowych do VAS = 7. Do przyjmowanych przez kobietę leków postanowiono dołączyć pregabalinę, zatem schemat dawkowania leków był następujący - Amitryptyline hydrochloride - $45 \mathrm{mg} /$ dobę oraz pregabalina $-75 \mathrm{mg} /$ dobę.

\section{Wizyta 13.}

Wizyta 13. miała miejsce po 7 dniach od 12. wizyty. Pacjentka nie miała dolegliwości bólowych (VAS = 0) pod warunkiem ścisłego przestrzegania diety bez cytrusów i błonnika oraz 
użytkowania szyny i przyjmowania przepisanych leków. Schemat dawkowania został pozostawiony bez zmian: Amitryptyline hydrochloride $-45 \mathrm{mg} /$ dobę oraz pregabalina $75 \mathrm{mg} /$ dobę.

Od 1,5 roku pacjentka zgłasza się na regularne wizyty kontrolne co 3 miesiące i cieszy się dobrym samopoczuciem oraz brakiem dolegliwości bólowych. Schemat przyjmowanych leków pozostaje bez zmian.

\section{PODSUMOWANIE}

Częsta ingerencja chirurgiczna w tej samej okolicy anatomicznej, położonej w nieznacznej odległości od pnia nerwu obwodowego, zwiększa ryzyko wystąpienia przewlekłych dolegliwości bólowych, opornych na leczenie klasycznymi lekami z grupy NLPZ. Poza odpowiednim uśmierzeniem bólu, przebijającego w okresie krótko po zabiegu, szczególnie istotne jest niedopuszczenie do wystąpienia przewlekłych dolegliwości, które utrzymując się powyżej 3 miesięcy, zaczynają nosić cechy bólu neuropatycznego, stając się tym samym bardzo opornymi na leczenie $[1,2,3,4,5,6]$. Pacjentka opisana powyżej była również konsultowana przez lekarza neurologa, który potwierdził neuropatyczny charakter bólu. Wymienionym postępowaniem udało się praktycznie wyeliminować dolegliwości, co niestety nie jest jednak dla takich przypadków regułą. Pomimo przewlekłego przyjmowania leków średni poziom redukcji natężenia odczuwanych bodźców bólowych przy skutecznej, multimodalnej terapii bólu neuropatycznego u takich pacjentów wynosi zwykle ok. 50-60\% [2, 4].

\section{PIŚMIENNICTWO}

1. Samuels AM, Ropper HA. Leczenie w neurologii. 1st ed. Wrocław: Elsevier Urban \& Partner; 2014.

2. Sharav Y, Benoliel R. Orofacial pain and headache. 2nd ed. Elsevier; 2016.

3. Bannister R. Neurologia kliniczna. 7nd ed. Bielsko-Biała: Wydawnictwo Alfa-Medica Press; 1992.

4. Okeson JP. Managment of temporomandibular disorders and occlusion. 7nd ed. Elsevier Science Publishers; 2012.

5. Al-Quliti KW. Update on neuropathic pain treatment for trigeminal neuralgia. The pharmacological and surgical options. Neurosciences (Riyadh) 2015;20(2):107-14. doi: 10.17712/nsj.2015.2.20140501.

6. Gallagher HC, Gallagher RM, Butler M, Buggy DJ, Henman MC. Venlafaxine for neuropathic pain in adults. Cochrane Database Syst Rev 2015;23(8):CD011091. doi: 10.1002/14651858.CD011091.pub2.

7. Bharti Ch, Bairy KL, Smitha D, Supurna D, Himabindu P. Comparision of the efficiacy of carbamezapine, gabapentin and lamotrygine for neuropathic pain in rats. Indian J Pharmacol 2011;43(5):596-8.

8. Sidhu HS, Sadhotra A. Current status of the new antiepileptic drugs in chronic pain. Front Pharmacol 2016;7:276. doi: 10.3389/fphar.2016.00276.

9. Clark GT, Padilla M, Dionne R. Medication treatment efficacy and chronic orofacial pain. Oral Maxillofac Surg Clin North Am 2016;28(3):409-21.

10. Berge TI. Incidence of chronic neuropathic pain subsequent to surgical removal of impacted third molars. Acta Odontol Scand 2002;60(2):108-12.

11. Dieleman JP, Kreklaan J, Huygen FJ, Bouma PA, Sturkenboom MC. Incidence rates and treatment of neuropathic pain conditions in the general population. Pain 2008;137(3):681-8. doi: 10.1016/j.pain.2008.03.002.

12. Koopman JS, Dieleman JP, Huygen FJ, de Mos M, Martin CG, Sturkenboom MC. Incidence of facial pain in the general population. Pain 2009;147(1-3):122-7. doi: 10.1016/j.pain.2009.08.023.

13. González Canga A, Fernández Martínez N, Sahagún Prieto AM, García Vieitez JJ, Díez Liébana MJ, Díez Láiz R, et al. Dietary fiber and its interaction with drugs, Nutr Hosp 2010;25(5):535-9. doi: 10.3305/ nh.2010.25.4.4610.

14. Ju Z, Cui H, Guo X, Yang H, He J, Wang K. Molecular mechanisms underlying the effects of acupuncture on neuropathic pain. Neural Regen Res 2013;8(25):2350-9. doi: 10.3969/j.issn. 